\title{
A invenção da violência
}

MUCCHIELLI, Laurent. L'invention de la violence: des peurs, des chiffres, des faits. Paris: Fayard, 2011, pp.340.

\section{Resumo}

Apresentamos a obra do sociólogo francês Laurent Mucchielli ${ }^{1}$, L'invention de la violence: des peurs, des chiffres, des faits (2011), que analisa o debate público e acadêmico sobre insegurança e violência na França. O livro se divide entre a reconstituição histórica das representações sobre o aumento da violência e a crítica do uso político de estatísticas sobre criminalidade, com foco principal no questionamento da interseção entre o "problema da delinquência juvenil" e o "problema da imigração". São analisadas as mudanças nas normas de comportamento, os processos de segregação urbana e a construção de novos mecanismos de atuação estatal na área da segurança pública. Em lugar de um pacote de soluções, o autor convida à indagação crítica sobre as transformações das últimas décadas e, com clareza de estilo, realiza uma síntese dos conhecimentos científicos na área.

Palavras-chave: Violência. Insegurança. Sociologia da Delinquência. Judicialização. Criminalização.

\footnotetext{
Universidade de São Paulo (Brasil)

${ }^{1}$ Sociólogo, diretor de pesquisa no Centre Nacional de Recherches Sociologiques (CNRS), no Laboratoire méditerranéen de sociologie. Ex- diretor do Centre d'Etudes Sociologiques sur les Droits et les Institutions Pénales (CESDIP) e diretor atual do Observatoire Regional de la Délinquance et des Contexts Sociaux (ORDCST), na Université Aix-Marseille. Possui também um site referência na organização de notícias, pesquisa e bibliografia na área da sociologia do desvio, do crime e da segurança pública: www.laurent-mucchielli.org.
} 


\begin{abstract}
Here we present the work of the French sociologist Laurent Mucchielli, L'Invention de la violence: des peurs, des chiffres, des faits (2011), which examines public and academic debate on insecurity and violence in France. The book is divided into the historical reconstruction of representations about the increase in violence and the critique of political use of crime statistics, focusing on the analysis of the intersection between "juvenile delinquency" and "immigration" as social problems. The author examines changes in behavior norms, processes of urban segregation and the construction of new mechanisms of state action in the area of public security. Instead of given solutions, the author invites to a critical inquiry into the last decades transformations and offers a clear synthesis of scientific knowledge in the area.
\end{abstract}

Keywords: Violence. Insecurity. Sociology of Delinquency. Judicialization. Criminalization.

O livro do sociólogo Laurent Mucchielli ${ }^{\square}$ oferece uma das mais completas, e também polêmicas, reconstituições do debate atual sobre violência e insegurança no contexto francês. Com recurso à abordagem histórica e estatística, o autor desvela as camadas de discursos e controvérsias que se acumularam em torno dos fatos, dados e ações que buscaram responder aos medos da sociedade francesa. O objetivo central do autor é traçar um caminho para atravessar a "grande confusão" que reinaria no debate público sobre o tema. Em meio à instrumentalização política, eleitoral e midiática, toda discussão derivaria para o compartilhamento de indignações, a busca de culpados, e mesmo bodes expiatórios, e a declarações de intenções permeadas por alto grau de moralismo, maniqueísmo e ideologização. Mas, em lugar de um pacote de soluções, o autor convida à indagação crítica sobre as transformações das últimas décadas e, com clareza de estilo, realiza uma síntese dos conhecimentos científicos na área. Apesar das diferenças em relação à realidade brasileira, vale a pena considerar a sua argumentação como possibilidade de paralelos futuros. 
Sociologias, Porto Alegre, ano 17, no 39, mai/ago 2015, p. 404-414

O desafio inicial seria o enfrentamento do imaginário da decadência ou declínio global da sociedade, um "clássico da história das ideias políticas", atualizado nos diagnósticos alarmistas da "insegurança crescente", da "violência que não cessa de aumentar". Nesse cenário, a insegurança objetiva - expressa na realidade da vitimização - se confundiria facilmente com um sentimento difuso de insegurança, ligado à sensação de vulnerabilidade ou medo diante de transformações gerais na vida social, como o envelhecimento da população, ou específicas do cenário urbano, e suas consequências em termos de signos exteriores de desordem e abandono. Dessa maneira, sua narrativa busca surpreender a invenção coletiva da violência em meio aos embates pela construção da memória e do futuro, que se expressariam de modo significativo na competição pela elaboração da visão legítima dos fenômenos e sua imposição através da direção política.

Nesse sentido, o próprio livro constitui arma de luta no interior das recentes controvérsias, ao mesmo tempo epistemológicas e políticas, que mobilizam o meio acadêmico francês a respeito do "amadorismo" ou da "manipulação" na comunicação dos "números da delinquência". Mucchielli toma como exemplo o anúncio das estatísticas oficiais feito pelo Ministro do Interior, todo mês de janeiro, as quais lança três críticas principais: 1) sua base em queixas à polícia e não em pesquisas de vitimização; 2) o alargamento da definição da delinquência e o agravamento de sua penalização com as leis promulgadas após 2002; e 3) a pressão de incentivo aos "bons números" a serem apresentados oficialmente. Em suma: os dados apresentados registrariam mais o funcionamento das organizações policiais, de acordo com definições operacionais e legais, do que as tendências reais da delinquência.

O alvo da crítica é o novo management da segurança pública implementado por Nicolas Sarkozy com o auxílio de "novos experts" e seus 
Sociologias, Porto Alegre, ano 17, no 39, mai/ago 2015, p. 404-414

apoios políticos e midiáticos" ${ }^{2 \prime}$. O caso mais evidente da ascensão destes "pseudo-cientistas" seria a criação, por decreto, da cadeira de "criminologia" no Conservatoire National des Arts et Métiers, confiada à Alain Bauer $^{3 \prime}$, conselheiro de Sarkozy para assuntos de segurança pública. Nos anos seguintes, Mucchielli e Bauer serão as principais personagens da intensificação da "querela de experts" sobre os dados oficiais de delinquência, em uma disputa, ao mesmo tempo política e epistemológica, pela aceitação ou recusa da identidade da criminologia como campo de estudos, disciplina ou formação profissional, e pela criação de condições para a independência crítica do intelectual frente aos governos e ao mercado (BAUER, 2008; VILLERBU, 2009; MUCCHIELLI, 2010; 2014).

Apresentado o contexto e a intenção do livro, cabe agora descrever sua estrutura e argumento. Em sua primeira parte, o autor se volta à elaboração de representações sobre a delinquência na história francesa e aos mecanismos políticos e midiáticos ligados à denúncia da insegurança a partir dos anos 1970. O primeiro ponto em destaque é a antiguidade do debate sobre insegurança, que teria dominado o debate público francês ao menos em três momentos de "pânico moral" desde o fim do século XIX, com figures de dangerosité específicas: os criminosos loucos, os jovens e os estrangeiros (ou imigrantes). Mas o cenário contemporâneo teria sua emergência após o intervalo dos trente glorieuses années ${ }^{4 "}$, quando a preocupação com

\footnotetext{
${ }^{2}$ Estes experts ganhariam maior espaço com a criação do Observatoire National de la Délinquance e do Institut National des Hautes Étudessur la Sécurité et la Justice (INHESJ).

${ }^{3}$ Consultor do New York Police Department e do Los Angeles Sheriff Department. Professor do John Jay College de justice criminelle da Universidade de New York et na universidade de Direito de Beijing. Ex-proprietário de uma sociedade de segurança privada e co-autor de publicações junto a Xavier Raufer, antigo militante de extrema-direita, combatente das explicaçõessociológicas da delinquência, com ênfase na condenação da imigração e do crime organizado como problema maior.

${ }^{4}$ A expressão se refere ao intervalo de 1950 a 1980, que corresponde a fase de crescimento econômico, de constituição de um Estado-Providência e de uma sociedade salarial, e de fim das guerras de descolonização na França.
} 
Sociologias, Porto Alegre, ano 17, no 39, mai/ago 2015, p. 404-414

a ordem não se revela através da questão do aumento de roubos ou agressões físicas, mas da repressão a manifestações políticas e sindicais, radicalizadas no maio de 68 . Esse cenário daria seus primeiros sinais de mudança na virada dos anos 1970 e 1980, com a discussão da lei parlamentar Sécurité et Liberté de insegurança, mas cujo diagnóstico foi duramente combatido. Nos anos 1980 a questão viria então a se confinar à agenda da extrema-direita, que ganhava terreno explorando o tema do combate à imigração.

Mucchielli se dedica especialmente às representações que enxergam o aumento da violência na interseção entre os temas da delinquência juvenil e da imigração. Quanto ao primeiro, os discursos de senso comum apontariam para uma violência maior, armada e "gratuita", praticada por um número cada vez maior de garotos e garotas cada vez mais jovens, que dominam zones de non-droit por conta do laxisme da justiça. Tais percepções seriam apropriadas em iniciativas políticas que visaram revisar a legislação de proteção à juventude para incorporar novos mecanismos de prevenção da delinquência juvenil. Contra tal projeto, Mucchielli fornece uma outra leitura para os dados sobre o fenômeno: se a estrutura dos registros sobre delinquência juvenil se modificou ao longo dos 30 anos, esta mudança se deveria tanto a um aumento geral de escala dos delitos praticados tanto por adultos como por jovens, mas principalmente pela maior pressão policial sobre este último contingente, em resposta ao alargamento das categorias de delitos e crimes de "ordem pública" ou incivilités, considerados de menor gravidade ${ }^{6}$. Tal alargamento se daria pela incorporação do ideal de tolerância zero, caracterizada como acentuação

\footnotetext{
${ }^{5}$ Apresentado pelo Ministro da Justiça (garde des Sceaux), Alain Peyrefitte, com base em relatório de comissão governamental, Réponses à la violence, publicado em 1977. A lei é adotada em 1980, mas anulada em 1981, diante da forte resistência da esquerda.

${ }^{6}$ Como uso de drogas, vandalismo, atos desrespeitosos, insultos, ameaças, rixas, brigas e confronto ou desacato a policiais.
} 
Sociologias, Porto Alegre, ano 17, no 39, mai/ago 2015, p. 404-414

da repressão penal acompanhada do recuo de políticas sociais, em grande parte decorrente da abertura propiciada ao tema segurança pública por quadros partidários de esquerda nos anos 1990.

As pesquisas feitas com base em dados de vitimização e de "delinquência autodeclarada", ao contrário, não demonstrariam o propalado aumento da delinquência juvenil, mas sim a normalidade sociológica de certas transgressões e condutas de risco no quadro de processos de socialização de uma juventude, exposta pela precariedade de seus locais de habitação e pela "cultura de rua", característica antiga de bairros populares. Uma identidade desviante, fundada na defesa da reputação e da honra e na performance da coragem e da virilidade, assumida por vezes como identidade delinquente, mas nada semelhante ao quadro de "novas máfias" de jovens violentos no controle da economia da droga e da vida social em certas regiões da cidade.

É nesse ponto que a representação da delinquência juvenil se encontra com a construção do "problema da imigração", um amálgama propício para derivas xenofóbicas. Na exploração midiático-eleitoral das violences urbaines ${ }^{7}$ cometidas pelos jeunes des cités ou jeunes des banlieues tornaria flagrante como a construção da memória e da identidade francesa andou de costas para a contribuição da massiva mestiçagem e imigração ocorridos no século XX, em grande parte como mão-de-obra necessária à industrialização do país ${ }^{8}$. O cenário atual, nesse sentido, seria mais um capítulo da instrumentalização política do medo do estrangeiro, direcionado atualmente ora para os Roms e Tziganes - populações desprovidas de Estado,

\footnotetext{
Atos de protestos (émeutes), especialmente de jovens das periferias das grandes cidades francesas (cités ou banlieues) e descendentes de famílias imigrantes.

${ }^{8} \mathrm{O}$ mito das "raízes gaulesas", reforçado pelo sistema escolar, contrastaria com a contribuição de levas de imigração - belga e italiana no início do século XX, polonesa, espanhola e norte-africana no entre-guerras, e portuguesa e magrebina após 1945.
} 
representação diplomática ou associativismo transnacional-, ora para as populações de origem árabe e de religião islâmica. Apontar os jovens delinquentes issus de l'imigration como representantes do perigo social, seria um duplo erro de lógica, ao apontar para uma suposta natureza desviante e criminal de um contingente de $1 / 6$ da população francesa, reforçada por uma sobrerrepresentação de franceses de "origem estrangeira" nas estatísticas oficiais. Para Mucchielli, antes que aumento de delinquência, não constatado em geral, o fenômeno principal seriam os conflitos entre estes jovens e autoridades públicas (policiais e escolares), revelação de um conflito político e social a atravessar a sociedade francesa, expresso nas émeutes, interpretado como violences urbaines, na linguagem do Estado.

A segunda parte do livro busca um balanço das violências e delinquências na França, em duas abordagens. A primeira, histórica, parte do pressuposto de que os conhecimentos científicos disponíveis não confirmam a ideia de um aumento permanente da violência, sendo necessário refletir sobre a "amnésia coletiva" a respeito das violências no passado. Desde a dissolução da ordem feudal ${ }^{9}$, a tendência seria de baixa das violências físicas interpessoais, com aumento de crimes de propriedade e judicialização das relações privadas a partir do século XIX. Com relação ao século XX e à delinquência juvenil, a sua constatação seria a da recorrência do "pânico moral", em primeiro lugar com os apaches, grupos de jovens pobres que atuam em bando nos anos 1900-1910, e com os blousons noirs, grupos de jovens que aderem à cultura do consumo e da rebeldia nos anos 1950-60, organizam-se em grupos rivais, cometem vandalismos e roubos de bens, como automóveis e motocicletas. Ao mesmo tempo, a época atual teria visto o recuo das violências políticas, presentes antes da Segunda Guerra,

${ }^{9} \mathrm{O}$ seu ponto de partida é a violência física rotineira, presente nos séculos de dissolução da ordem feudal, marcados por invasões estrangeiras, pela proliferação de grupos de bandidos nas rotas de comércio, e por homens frequentemente armados e prontos para reagir em nome da defesa da honra. 
Sociologias, Porto Alegre, ano 17, no 39, mai/ago 2015, p. 404-414

mas também nos anos 1970, nos conflitos entre forças da ordem e trabalhadores, e entre grupos estudantis de esquerda e extrema-direita.

Este contraste apontaria para o diagnóstico paradoxal do período contemporâneo como um dos menos perigosos da história francesa. Para comprovar esta tese, com base em pesquisas de vitimização, Mucchielli analisa quatro tipos de violência: o homicídio, que veria uma diminuição progressiva que teria passado desapercebida (queda pela metade em 15 anos, 1985 a 2010); os estupros, que teriam seu aumento estatístico explicado pelo maior número de denúncias na esteira da afirmação dos direitos femininos e judicialização dos conflitos; e as agressões físicas não fatais (golpes e ferimentos) e os roubos, que teriam se mantido estáveis. Além de propor uma melhor qualificação dos dados (e de sua comunicação), com sistematização das diferentes motivações e contextos envolvidos nos vários tipos de violência elencados, o autor conclui esta seção com a denúncia de uma desigualdade flagrante entre a grande atenção concedida à delinquência dos pobres e o pouco destaque à luta contra a delinquência econômica e financeira, mantida na impunidade.

Em sua terceira parte, o livro oferece uma leitura da evolução da sociedade francesa em busca de uma resposta à flagrante diferença entre a representação do aumento da violência e a realidade objetiva da diminuição ou estabilidade dos dados de delinquência e vitimização. Para tanto, Mucchielli propõe um modelo sócio-histórico através articulação entre cinco processos transversais, que explicariam as diferenças de origem, extensão e ritmo entre a evolução dos problemas de delinquência e sua percepção pela sociedade.

O primeiro diz respeito a um processo societário de "pacificação de costumes"10. Teria havido uma mudança das sensibilidades e das nor-

10Para ilustrar o que entende por este processo, ele se utiliza do "paradoxo de Tocqueville": Quanto mais um fenômeno desagradável diminui, mais o que dele resta é percebido ou vivido como insu- 
mas de comportamento, com a diminuição da tolerância com o uso da violência física nos conflitos, cuja regulação é cada vez mais delegada ao Estado. A deslegitimação do recurso à violência acompanharia, de um lado, com a distância geracional em relação à experiência da guerra, e de outro, com a ação de movimentos sociais de denúncia de violência. Sendo as violências privadas cada vez mais publicizadas, aumenta-se a empatia moral em relação às vítimas e seu sofrimento, em uma verdadeira competição entre grupos sociais pelas garantias e restituições oferecidas por este lugar simbólico e jurídico ${ }^{11}$.

Em consequência, teríamos uma resposta do Estado em termos de um processo político-jurídico de disciplinamento pela criminalização. Ao menos desde a reforma do Código Penal (1992-1994) haveria uma acelerada criação de categorias criminais, que se intensificaria após 2002, com ênfase na proteção à integridade física, acompanhado do aumento das penas. Além disso, o incentivo à incorporação da ideia de tolerância zero por parte da chaîne pénale (policiais, juízes e operadores do direito) traria como consequência o afrouxamento do controle sobre processos investigativos policiais, como o aumento dos gardes à vue ${ }^{12}$ e o desenvol-

\footnotetext{
portável. Mucchielli tem como referência a teoria da "civilização dos costumes", de Norbert Elias, mas tomando uma relativa distância. Para ele, inspirada pela psicanálise freudiana (luta entre a violência das pulsões fundamentais e da moral do superego) e por um modelo difusionista unívoco (normas aristocráticas se difundindo progressivamente às camadas sociais menos elevadas), a teoria psicossociológica de Elias carregaria a marca de seu tempo. Além do conceito de civilisation carregar pressupostos normativos, ele seria ainda insuficiente para explicar a grande redução do nível de violências interpessoais desde o fim da Idade Média, embora seja fundamental para entender a mudança do estatuto da violência e sua relação com as normas de comportamento.

${ }^{11}$ A esta altura poderíamos indagar por um maior aprofundamento da questão do monopólio da violência física legítima frente às mudanças da últimas décadas, em contrastes ou correlação com a emergência de um "novo paradigma da violência" (Wieviorka, 1997). Poderíamos ainda apontar o pouco enquadramento dos fenômenos da criminalidade organizada e do tráfico de drogas como objetos de conhecimento, para além da invalidação de sua imagem como "ameaça à sociedade". ${ }^{12}$ A garde à vue consiste em uma medida privativa de liberdade de duração estritamente limitada de uma pessoa suspeita de ter cometido um crime, realizada pelas forças de polícia no quadro de uma investigação judicial.
} 
Sociologias, Porto Alegre, ano 17, no 39, mai/ago 2015, p. 404-414

vimento de modos rápidos de sanção no tratamento da pequena delinquência. Tais fatores se fariam sentir como judicialização dos conflitos na vida social, o terceiro processo abordado, decorrente da oferta do recurso policial e penal aos profissionais da gestão social/educativa.

Mas este quadro só estaria completo com a associação entre as consequências da "periurbanização" recente e a competição por bens de consumo, os últimos dois processos do quadro analítico proposto pelo autor. O primeiro, também nomeado de segregação socioeconômico-espacial ou ghettoïsation, seria caracterizado pela construção de espaços de habitação e comércio padronizados na periferia das grandes cidades, os quartiers sensibles, marcados pelo "confinamento" de "cidadãos franceses de origem estrangeira", pela degradação dos serviços (lazer, segurança, transporte e educação) e pela pouca oferta de emprego. Haveria, com isso, a diminuição da capacidade de regulação de conflitos de vizinhança e a "anonimização" ou quebra dos laços sociais de proximidade. O segundo, por sua vez, diz respeito à expansão de uma sociedade de consumo, pautado pelo paradoxo entre desigualdade sócio-econômica estrutural e o convite à afirmação da individualidade através de produtos símbolos de status. Mucchielli utiliza pressupostos da sociologia norte-americana da delinquência para a compreensão da frustração diante de metas inalcançáveis de ascensão social como origem de comportamentos desviantes, a exemplo da "redistribuição violenta" através do roubo. Dessa maneira, em uma situação de pane no "elevador social" - segregação, desemprego e fracasso escolar -, a repulsa da violência física dos espaços íntimos da vida social passaria a conviver com o aumento do roubo violento e com o acirramento de percepções acerca do racismo e sentimento de injustiça e desconfiança em relação às instituições públicas por parte da juventude dos quartiers sensibles. Ao mesmo tempo, o reforço à au- 
toridade e o governo com base no medo como "solução" induziriam o aumento dos confrontos públicos e reforçariam o processo de estigma e segregação em curso. Isto se expressaria, por sua vez, na construção das estatísticas oficiais e na recusa governamental em refletir sobre as causas sociais da delinquência, vista como suspeita de incentivar a desresponsabilização dos indivíduos.

Como raciocínio conclusivo desse convite à leitura, vale ressaltar que a argumentação de Mucchielli coaduna-se com análises importantes da emergência de um paradigma penal concorrente ao que teria predominado entre 1945 e 1995, período de equilíbrio entre correntes de ideias penais e criminológicas cujo princípio residiu na compreensão das causas sociais da criminalidade, na humanização da pena e na reabilitação do criminoso (ENGUÉLÉGUÉLÉ, 1998). Nesse sentido, sua análise nos conduz a refletir sobre as novas prioridades das políticas penais, cada vez mais orientadas por uma "retórica securitária".

Francisco Thiago Rocha Vasconcelos - Doutor em Sociologia (Universidade de São Paulo), estágio-sanduíche no Centre de Recherches Sociologiques sur le Droit et les Institutions Pénales (CESDIP). $R_{\mathrm{ft}}$ rocha@yahoo.com.br

\section{Referências}

1. BAUER, Alain Bauer. Déceler-Étudier-Former: une voie nouvelle pour la recherche stratégique. Rapport au Président de la République et au Premier Ministre, 2008.

2. ENGUÉLÉGUÉLÉ, Stéphane. Les politiques pénales (1958-1995). Paris: L'Harmattan, 1998.

3. MUCCHIELLI, Laurent. Vers une criminologie d'Etat en France? Institutions, acteurs et doctrines d'une nouvelle science policière. In: Politix. Revue des sciences sociales du politique, 23 (1), 2010, p. 195-214.

4. MUCCHIELLI, Laurent. Criminologie et lobby sécuritaire: une controverse française. Paris: La dispute, 2014. 


\section{SOCIOLOGIAS}

Sociologias, Porto Alegre, ano 17, no 39, mai/ago 2015, p. 404-414

5. VILLERBU, Loïc (ed.). La babel criminologique. Paris, I'Harmattan, 2009.

6. WIEVIORKA, Michel. O novo paradigma da violência. In: Tempo social, São Paulo, v. 9, n. 1, May 1997.

Recebido em: 06/11/2014

Aceite Final: 06/03/2015 